\section{THE ELDERLY DANE}

BY

\author{
RONALD GIBSON, M.A., M.R.C.S \\ General Practitioner, Winchester, Hants
}

In April, 1959, I visited Denmark to study the welfare services over there, particularly in relation to the care of the elderly and the organization of the medical profession. Great kindness and generosity were shown to me by all those on whom I called. The Danes are a courteous and gentle people who have almost unlimited patience to spare for the inquisitive student.

I learnt a great deal during my visit. It was entirely personal research, and I am sure that much of what I write will not be original ; moreover, my discoveries may not be of any use to anyone but myself.

I have done my best to be accurate. Where I have been in doubt I have tried to confirm the facts by asking the same question of several people; where their replies have differed I have either omitted the point altogether or quoted more than one answer.

As a State employee I should have been very shortsighted had I not noted during my studies certain other aspects of the Danish welfare state which, even if they have no direct bearing on my subject, are too attractive to be allowed to pass without comment.

Just before I left for Denmark I listened to Sir Keith Joseph delivering the Winchester Address, entitled "The Citizen and the Welfare State." He said that the welfare services formed more of a welfare archipelago than a welfare state. He quoted from the Report of the National Corporation for the Care of Old People for 1958, which states: "To bring about a properly integrated system of social services it is necessary for all who are engaged therein at every level to work in close co-operation; and to do this they must first make the effort to discover, not only their own problems and how they can best be overcome, but also what is being done by social workers in fields which are adjacent to, and even overlapping, their own. . . . The services for old people are the responsibility of four different governmental departments, and the plans which each makes for the future will have an effect both on those made by the others, by whom they must be taken into account, as well as on the whole problem of the carè of old people."

Sir Keith then went on to quote a report prepared by Dr. Boucher, of the Ministry of Health, which was published in 1957. He said that " in a trenchant sentence Dr. Boucher comes to this devastating conclusion: "The position was such that in some areas able-bodied persons were living in welfare homes, the frail ambulant were occupying hospital beds, while chronic sick were dying at home under bad conditions because hospital admissions could not be arranged."

Sir Keith summed up by saying that there were therefore these two great problems in the whole health and welfare field (which he had illustrated particularly in connexion with the elderly): co-ordination of policy and co-ordination of performance. He then recommended (amongst other things) the creation of a Minister of Social Service with Cabinet rank.

The day I arrived in Denmark I saw a bold headline in the Daily Telegraph: "Unified Service Urged for Care of Aged Sick." Below this was an article on a booklet by C. P. Blacker (1959). His theme is that hospital and local health authorities and family doctors should get together to achieve co-ordination of the services available for caring for the old and infirm-to create a single, unified service. Policy should be decided by local groups of representatives of official and voluntary organizations. He recommends the appointment of an old people's officer, analogous with the children's officer now employed by local authorities.

I was in the capital city of a country which practised co-ordination. I believed wholeheartedly in the urgent need for it in my own country.

\section{Denmark}

The Kingdom of Denmark consists of the peninsula of Jutland and 500 small and large islands, about 100 of which are inhabited. The area of the country is some 16,600 square miles $(42,994$ square $\mathrm{km}$.). Since A.D. 900 it had been an independent kingdom, with the introduction of a constitutional monarchy in 1901, in which freedom of democratic rights is guaranteed. A Parliamentary government has existed since 1901 . The central administration is in the hands of responsible ministers and their Departments of State. It is represented in each of the 22 counties by county governors.

Municipal self-government plays an important part. Local authorities (and there are some 1,400 local administrative units) have the sole charge of a number of important tasks, not the least of which is the care of the elderly: The expenditure on social services is in all essentials paid by the municipal authorities, by means of reimbursements from the State.

In 1958 the population was 4,500,700, of whom 456,700 were over 65 years of age. It is calculated that by 1970 the population will have increased to $4,889,100$, with 563,600 aged 65 or over.

There are approximately 265 persons per square mile in Denmark, as opposed to 50 in the United States and 530 in the United Kingdom. Approximately 944,100 of the total population live in Copenhagen, which could tend to make administration a little top-heavy.

One hundred years ago the population was $1,400,000$. Annual growth in the population is at the rate of about $1 \%$; the birth rate being 18 per thousand, and the death rate 9 per thousand.

In 1955 , of $1,385,130$ houses, 54,940 contained one room, 368,230 two rooms, and 130,570 six rooms or more. The largest group $(425,350)$ contained four rooms. More than once the handicap of so many small houses was mentioned to me, since this was one of the reasons why families were unable to care for their older relatives.

\section{Administration}

The administration of the health service in Denmark comes under the authority of a department known as the National Health Service (I found this most confusing at first). This has a medical director (not a Minister), Dr. Johs. Frandsen, and everywhere I went I heard expressions of respect for and confidence in this man, who corresponds to our Minister of Health. In Britain, where the Minister is looked upon as our employer, we may respect a particular minister yet regard his department with mistrust and misgiving. In Denmark Dr. Frandsen's department (as explained later) does not employ the doctors, and in consequence they look upon him as a colleague to whom they can turn for help, advice, and support, and as one who is as 
anxious as they are to create the best possiole health service for the community. A positive atmosphere of co-operation exists, whereas in Britain there is the appearance of an almost perpetual schism. In Denmark the public accepts a health service which results from the combined efforts of Health Ministry and doctors-in Britain our patients watch the wrangling that has become almost an accepted adjunct to every step that is initiated by one side or the other to improve the service.

The "National Health Service" of Denmark, as an administrative unit, belongs to the Ministry of Internal Affairs (our Home Office). The Danes regard the problems of health as too widespread and too involved to be collected in one ministry-the consequence is that they have evolved a National Health Service which acts in an advisory capacity to all branches of administration where problems of health are concerned, and, in the case of the elderly, plays such a part to the Ministry of Social Affairs.

All the social services in Denmark are under the control of a Minister of Social Affairs. In each municipality there is a department of social affairs which in larger towns is controlled by a director and in smaller areas by an inspector. The staff of these departments includes a social doctor (I rather gathered that this doctor was usually a psychiatrist and that this was not necessarily proving satisfactory-a less specialized medical opinion often being required).

In 1955-6 the expenditure on the social services amounted to $1,116.4 \mathrm{~m}$. kroner by the State and $456.7 \mathrm{~m}$ by the municipalities ( $f 1$ equals $19.36 \mathrm{kr}$.). Of the social expenditure $40 \%$ goes to the old people and represents one-eighth of the total budget-quite a large item.

The total extent of the problem is that the State is caring for $9 \%$ (or $8.8 \%$ ) of the old people, of whom 20.000 are in chronic sick hospitals and 15,000 in old people's homes. There is quite a long waiting-list for State accommodation (a figure quoted to me was that there were between 11,000 and 12,000 flats accommodating about $5 \%$ of all old-age pensioners, and there might be a waiting-list of 600 , of whom 100 would be in real need).

\section{Old-age Pensions}

There are 280,000 old people drawing old-age pensions, or $58 \%$ of the total number of persons of pensionable age. The right to pension is not subject to the condition that the person concerned has paid pension contributions. The guiding consideration is that the pension should be sufficient to enable the pensioner to manage without any other assistance from local authorities, private societies, or individuals. The pensions are subject to automatic adjustment for changes in the cost-of-living index.

The minimum rate for a married couple is $9 \%$ of the average gross income for bread-winners, and two-thirds of that amount for single persons. The cost of these pensions was estimated at about $1,000 \mathrm{~m}$. $\mathrm{kr}$. in 1958 .

The qualifying minimum age is 62 years for single women and 67 years for all others. Applications for pension may be made from the 60th year in case of infirmity or other special circumstances.

The applicant for an old-age pension must be an active or passive member of a State-recognized health insurance fund or State-supervised health insurance society, and every Danish national is required to be at least a passive membor of a health insurance fund. The right to the minimum rate of the national pension is not subject to membership of the national health insurance.

Married couples in Copenhagen receive approximately $£ 260$ per annum; in rural areas the equivalent amount would be about $£ 226$ per annum. A single person's pension is in the neighbourhood of $£ 170$ per annum.

A person may postpone his application for old-age pension, in which case he receives a waiting supplement amounting to $10 \%$ of the basic pension at the 70 th year, and $15 \%$ after the 72 nd year $(65$ th and 72 nd year for the female).

\section{Care of the Elderly}

It is the intention of the Danish Government (as with our Government) that, wherever and whenever possible. the elderly should be cared fc: in their own homes.

In Pamphlet No. 5 on the Danish Social Structure, published by the Danish Institute, one reads: "With the passing time doubts have been expressed as to the desirability of gathering numbers of old people in large blocks where they have no direct contact with the other citizens of the community." Since 1951, therefore provision has been made for non-profit-making housing societies to let flats to old-age pensioners at a rent fixed by the Ministry of Social Affairs; the competent local authority makes up the difference in rent to the Society: About 500 flats are let to pensioners in this way, so that they are not confined to a single-group environment but are among people of all generations.

As I have already said, the home accommodation available is often the most serious obstacle. On more than one occasion I asked whether relatives who were anxious to keep their old folks with them but were in financial difficulty could be given any State help. I was told that officially the answer was "No," and that, in fact, it would rarely be necessary, since the elderly relatives would be drawing pensions and might even have a small private income of their own. But I also gathered that "unofficial " help might be given (in one case, for example, relatives were paid $300 \mathrm{kr}$. a month to help with the maintenance of an aged parent).

The services of the district nurse are available to help in the home, and also the home help. The problem of night care is as difficult in Denmark as in Britain (and is another reason for having to resort to State homes or hospitals).

One of the specific tasks of health visitors in Britain is to look after the elderly, but in Denmark they are not concerned with the older members of the population. They are in short supply. Municipalities are not compelled to have them, and only $66 \%$ have accepted them so far, though I was assured that $99 \%$ of the population appreciated their services when available. Knowing, what a valuable addition these health nurses are to the team in Britain, I felt rather sorry that they could not be more widely used in Denmark.

The Church, which can be so helpful in Britainarranging for sitting-in, mending, cooking, reading, an's so on-did not receive much favourable commen:, though there are special Church nurses in some areas. I wondered whether this might be due to the fact that all Danes pay a tax towards the Church, which may, I suppose, tend to give it the flavour of a nationalized industry. I hope this is not too harsh a comment.

There are a certain number of privately owned homes for the elderly run, possibly, by insurance companies 
or the like. These, on the whole, seem very satisfactory, One excellent side to these is that the municipality may pay up to $700 \mathrm{kr}$. a month to retain old people in these homes, rather than move them to a State establishment. I was most impressed by this. The Minister of Social Affairs has a measure of control over privately owned homes and can insist on a certain standard of care.

Old people who cannot get into homes and are living on their own are known to the social affairs department and can therefore be carefully supervised. They have a maintenance allowance, rent allowance, lighting and gas allowance, an extra allowance for special diets, milk, and clothing-all paid through the social committees from public assistance.

\section{The Old People's Town}

My first visit was to the Old People's Town in Copenhagen. I must confess to a certain amount of disappointment on seeing this, together with a feeling of apprehension. I was disappointed because, in fact, this is not a town. It is a large old people's institution, divided into three separate sections-for the independent, the semi-dependent, and the dependent. There are no shops.

I was apprehensive because of the vastness of this institution and the inherent danger of the individual old person being swallowed up within its walls, and its very vastness gave it the impression of being shut off from the world-an impression which was encouraged by the fact that the tendency is to take only the "elderly elderly" in here-that is, those in the late seventies and eighties. I was apprehensive, too, because I could see no end to it. Already it is being enlarged, and, so far as I can see, building will never stop, for as soon as one block is finished another will be needed.

My apprehension was shared, I believe, by others. As I have already said, it is now recognized that the ideal environment for the elderly, whether sick or well, is their own four walls in an open community, and nothing could be further from this than the Old People's Town. But, once having started it, there is no hope of stopping its expansion short of its complete destruction -and it would be a brave Dane who suggested such a step after so much has already been spent on the project.

This is painful criticism, for it would be impossibie to exaggerate the good intentions that have gone into this "town" and the excellent work that is done there. Those in charge of it have a vocation and are dedicated to the task of doing everything they can to bring comfort to these old people in their declining years. They are undoubtedly succeeding (as they deserve to), but this method of caring for the elderly is, I am sure, quite contrary to modern concepts.

The town has been in use in its present form since 1919 and covers 26 acres (10.5 hectares). There is accommodation for 300 semi-dependent persons and a hospital of 500 beds for the dependent. The remainder are independent, the total inhabitants now numbering 1,650 - to be increased to 1,830 when the present new building is completed.

I saw some of these old people in the single-room accommodation for the independent. In these they can be provided with furniture either in whole or in part, according to whether they wish to bring any of their own with them or not. There are four floors to the new building (housing 314), which are connected by lifts. There are small ante-rooms for washing, and section kitchens in which pensioners can provide themselves with extra cups of tea, and so on, if required.

There is a charmingly decorated and furnished sittingroom on each floor, which is equipped with wireless, magazines, and newspapers. In case of emergency a nurse can be called by means of an electrical signal system from each room.

No work is expected of the pensioners, but those who are able and willing to work can be given small jobs to do, for which they receive a little pocket money. I saw the 25 gardens which they can cultivate if they are so minded.

There are very few restrictions. The old people can go to stay with relatives or friends for up to one month at a time, and during the year they are allowed 21 days' board at $2 \frac{1}{2} \mathrm{kr}$. a day. There is a library, a church, and an entertainment hall for concerts, theatrical performances, or cinema shows. Pensioners without any private income receive $34 \mathrm{kr}$. a month as a personal allowance.

The block for the semi-dependent pensioners houses approximately 300 inhabitants. On each floor there are a nurse and two nursing aids. Husband and wife are still accommodated together. The men wear grey suits and the women blue print frocks.

In the hospital section there are 500 beds. The wards have 2 to 10 beds each. Ambulant patients have sittingrooms and smoking-rooms on each floor, and again husband and wife are kept together. There is a separate building for mentally sick patients, those with confused states, and so on.

Speaking to the matron and to Dr. Lünd, I was impressed by their nursing problem. At present girls are recruited from their homes (or "off the streets," as they said) with no previous nursing experience. There is a general shortage of nurses. Matron is most anxious to have a training school attached to the Old People's Town. Her idea is that these raw recruits should be given a month's training in hygiene and moral principles, then should graduate to the wards for at least a year's hospital training, and finally could stay on in her hospital or be transferred to work in other hospitals coping with elderly people. In this way she would build up a team of fully trained geriatric nurses.

I was particularly excited by this idea, and decidec' to pursue it. I therefore included it in my list of questions to other people-Was there a place or a need for specially trained geriatric nurses? The Director of the Social School in Copenhagen thought that with the increasing geriatric problem it might soon be necessary to have specially trained nurses both in hospitals and for home visiting. The Senior Medical Officer of Copenhagen agreed that there was a possible place for such nurses, and for the specially trained social worker in this field. In Aarhus the suggestion was also favourably received, but in the Ministry of Health I was told that such training was considered unnecessiry. My own view is that it is not only necessary but overdue both here and in Denmark.

From the Old People's Town I went to visit one of the 13 blocks of new flats for the elderly in Copenhagen. This was five stories high and had no lifts. The accommodation for each individual was excellent. There are over 6,000 apartments in these 13 blocks, with some 7,500 inhabitants. Each single person has one room with a kitchenette, the latter being very 
conveniently arranged to help the elderly. A married couple have two rooms and a kitchen.

In a separate building there is a delightful hall with modern kitchen and pantry, where pensioners can hold parties on birthdays and other special days-crockery, cutlery, and glass being provided. The rent, which includes central heating, is $64 \mathrm{kr}$. a month for a single person and $76 \mathrm{kr}$. for a married couple (their total pension being $452 \mathrm{kr}$. a month).

I was rather surprised to find that the bathroom was also in a separate block, and to hear that pensioners bathed twice monthly.

Occupants of the flats can also, if they so wish, have their meals supplied for them (one delivery arrived as I was walking round). They are cooked centrally and delivered to the main kitchen, there to be collected in individual small containers at a cost of $2 \mathrm{kr}$. a meal. I saw one of these meals ; it looked very appetizing.

\section{Responsibility}

I discussed "responsibility" with a number of people. I have always been afraid of the welfare state contracting this to such small proportions that marked injury is done to community life.

I was told in the Old People's Town that there was a falling off in the responsibility shown by the younger generation for their older relatives. They often had to be cajoled into visiting at all. Visits are precious things to pensioners, and the tendency for relatives to neglect them once they have been taken off their hands by the State is another reason for the condemnation of institutional life for the elderly, for I feel sure that the same lack of responsibility is not shown when parents or grandparents are given municipal flats or houses (whether these be in groups of similar accommodation or in an environment which includes all age-groups). Undoubtedly, as I have said, the modern movement is away from institutions - in Aarhus, for example, the municipality is hoping to make available to the elderly $10 \%$ of all new houses built.

In the Ministry of Social Affairs it was pointed out to me that it has never been a legal responsibility in Denmark for relatives to look after parents-it is a moral responsibility only. The moral responsibility is one which should be nourished by the State, and the way to do this, in the first place, is to keep the elderly in their own homes and independent of the State for as long as possible (even though this may entail giving financial and physical help to relatives or friends in some cases), and when, for one reason or another, they become utterly dependent on the State, to house them in such a way that the community can still take a large share in their well-being. This is done for children and invalids - why not for the elderly ?

On the whole I gained the impression that there was a lack of responsibility-shown only by the "feckless few," who might stand out more obviously in the welfare state but who nevertheless existed long before it came into being.

\section{Social School and Workhouses}

I visited the social school in Copenhagen, where social workers are trained for hospitals, public assistance, children's welfare, maternity aid, employment offices, and the like.

There are 20 "workhouses" left in Denmark. There is one-or what was described as the remainder of one-in Copenhagen. This might have to care for up to 50 people, mostly alcoholics and those who either refuse to accept the State pensions or are too profligate in the use of them.

\section{Aarhus}

I travelled to Aarhus by train. All the occupants of my carriage spoke excellent English. During the trip the tremendous pride the Dane has in his country was evident. (At one stage in a journey lasting six and a half hours it seemed that the train might be two and a half minutes late arriving at Aarhus. Fortunately-and I found myself joining in the excitement-the driver made up the time. Had he not done so I am sure there would have been a court of inquiry and a vote of censure. On the way home my train from Harwich to Liverpool Street was 25 minutes late, and only marmalade was served at tea-time. I never turned a hair.) They showed me their new buildings, their magnificent bridges, and their neat and tidy railway stations. They are proud of their welfare state but apprehensive of the level of taxation.

In Aarhus-the second largest city in Denmark-I had a close glimpse of the administration at work (on a Saturday morning). There is no comparable machinery in Britain. Here we divide up our social services so that they are spread over various departments, each under a different ministry, with no statutory allegiance to the others. In Aarhus all the social services come under the one ministry, whose local director, Mr. Jensen, has them in his complete control. We muddle through on an end-product very similar to the Danish pattern, but we should be prepared to learn from the Danes how to create this economically-from the point of view of time, man-power, and money.

On my tour I was escorted by one of the women social welfare workers employed by the local department of social security. She and her colleagues regularly visit the elderly and help them in all their problems.

There are three homes for the elderly in the city-one to house 40 persons (regarded as the ideal size), one with 62 inhabitants, and a third with 225 . This latter includes 137 sick-beds, and it is hoped soon to increase these and give this particular home the status of a hospital.

The flatlets, I thought, were ideal (with the exception that they were in three stories, without a lift). The matron in charge was prepared to look after cases of minor sickness, the more serious illnesses being transferred to the general hospital. Included in the "home" was a room for birthday parties, another for the entertainment of visitors, a small "bank" at which pensions could be collected to save walks to post offices, and a doctor's consulting-room.

I went from here to a block of flats housing both healthy old people and invalids. I saw blind residents and some suffering from such diseases as disseminated sclerosis, polyarthritis, and so on. I was very impressed by these flats, and particularly by the kitchenettes, especially designed to help the invalids. Occupational therapy was practised here, and patients were taken to the nearest hospital for physiotherapy, daily living activities, and so on. Home helps were provided either by the insurance clubs or by the municipality.

In addition to these homes, and those run privately, the municipality hopes to obtain $10 \%$ of all houses built, so that old people can continue to live in an environment comprising all generations. 


\section{Conclusions}

After 10 days of fairly intensive study I came to the following conclusions.

That the end-product in both Britain and Denmark - the picture of the welfare state as it is seen by the elderly, and as it is translated for the elderly-is very similar. Denmark has one tremendous advantage in that it provides what Sir Keith Joseph and others so much look forward to in Britain-co-ordination of policy and co-ordination of performance-due to the existence of a Ministry of Social Affairs, with departments of social affairs in the municipalities. I was so impressed by this and, in contrast, so confused by the traditional muddling through in Britain, that when all the pieces have been fitted in and the complete design appears it is surprising to find that old people here are in most respects as well cared for as the elderly in Denmark.

A further advantage to Denmark is that the smaller population can be much more easily organized. But the Danish machinery is so geared that it could cope with any number without impairing efficiency.

In both countries the basic policy is that care should be in the home for as long as possible and that when home care breaks down the alternative provided by the State should be set in an environment which includes all age-groups.

Both countries have, to my mind, set off on the wrong foot in arriving at their objective (or perhaps it would be more truthful to say that both countries had already set off on the wrong foot before they realized their objective) by building " hotels" or " towns" for the elderly which are expensive to run and, no matter how efficient and dedicated the staff, inevitably transfer old people from the security of their own homes to a oneage-group environment; from the seclusion to which they are accustomed to the publicity of " bedrooms" (or wards) which they are expected to share with strangers; to community feeding and a boarding-school atmosphere-all at the age at which they are least able to adapt themselves to change. (I am not the only family doctor, I am sure, who has seen such patients turn their faces to the wall rather than attempt to cope with this type of community existence.)

We have fallen more deeply into this pit than the Danes, for though the "Old People's Town" provides us with the best (or worst) example of this one-agegroup existence, yet even here the independent have their own private apartments until such time as they come to need constant care and supervision. Whereas in our " hotels," provided with television, lawns, writing-rooms, and the minimum of rules and regulations, not a trace can be found of the original home atmosphere from which the elderly inmate has been torn.

Moreover, Denmark is ahead of us in the measures taken to retain the elderly in their own homes: subsidizing flat or house rentals; supplementing allowances in privately owned nursing-homes ; giving " unofficial" help to relatives, and so on. They have the handicap of too many small houses and an inadequately matured health-visitor service.

I should like to see a proportion of all new houses built in this country set aside for the elderly, who should be made more financially secure by having their pensions adjusted according to the cost-of-living indexas in Denmark.
In both countries there is a need for more trained geriatric nurses and social workers, and there is a vital need for night care-without which care in the home inevitably breaks down sooner or later.

In short, though the end-result to the elderly may be the same in both countries, the Danes have more reason to be proud of their organization than we have, and we have much to learn from them.

I called on the Secretary of the Danish Medical Association (Dr. Fenger), the Ministry of Social Security, the National Health Service (Department of Health), the principal of a social school (Mr. Watt Boolsen), the Director of Social Security for Aarhus (Mr. Orla Jensen), the Chief Medical Officer for Copenhagen (Dr. Inge Jespersen), a distinguished general practitioner whose particular interest is in rehabilitation (Dr. F. E. Backer, to whom I am particularly grateful for his detailed description of the Danish National Health Service), the Medical Director and the Matron of the Old People's Town in Copenhagen (Dr. Lünd and Miss Ib-Hanson), and others. I was generously entertained by Dr. Hubner, the chairman of Messrs. Lundbeck \& Co. I took every possible opportunity to speak to "ordinary" men and women whom I met on particular occasions, so that I could get the views of the "man in the street" on the welfare state in which he lived.

Finally, I must record my very sincere gratitude to the British Embassy for the tremendous help given to me in arranging my programme, and for the entertainment given to those whom I visited; to the Secretary of the British Medical Association (Dr. D. P. Stevenson) for so kindly warning Denmark of my impending visit; to the College of General Practitioners for allowing me to represent them during my tour; to the Danish Institute; and to the British Council.

REFERENCES

Blacker, C. P. (1959). Mentally Infirm People Over Sixty-five. London.

Boucher, C. A. (1957). Rep. publ. Hlth med. Subj., No. 98.

\section{SUBACUTE BACTERIAL ENDOCARDITIS \\ BY}

\section{W. BARRITT, M.D., M.R.C.P.}

AND

W. A. GILLESPIE, M.D., F.R.C.P.I.

From the Departments of Medicine and Pathology, United Bristol Hospitals

This investigation began with a review of blood cultures in subacute bacterial endocarditis (S.B.E.) to determine the frequency with which the first cultures were positive. If the early cultures were usually positive it might be possible to recommend beginning antibiotic treatment before the results of culture were known.

In addition to the results of blood culture, we report some of the clinical features and the treatment of all cases of S.B.E. admitted to the United Bristol Hospitals during a period of eight and a half years. Five patients had been thought to have S.B.E., with persistently negative blood cultures, and their cases are considered in detail.

\section{Plan of Study}

The results of every blood culture performed between January 1, 1950, and July 31, 1958, were scrutinized and the hospital clinical records were studied of all patients in whom the diagnosis of S.B.E. had been made. Those with positive blood cultures are described in the first part of the paper. The second part deals with patients whose blood cultures were negative. As every blood culture has been recorded we feel that we have 